Comparison of risk-based versus random sampling in the monitoring of antimicrobial residues in Danish finishing pigs

Alban, Lis; Rugbjerg, Helene ; Petersen, Jesper Valentin; Nielsen, Liza Rosenbaum

Published in:

Preventive Veterinary Medicine

DOI:

10.1016/j.prevetmed.2016.04.007

Publication date:

2016

Document license:

Other

Citation for published version (APA):

Alban, L., Rugbjerg, H., Petersen, J. V., \& Nielsen, L. R. (2016). Comparison of risk-based versus random sampling in the monitoring of antimicrobial residues in Danish finishing pigs. Preventive Veterinary Medicine, 128, 87-94. https://doi.org/10.1016/j.prevetmed.2016.04.007 


\title{
Comparison of risk-based versus random sampling in the monitoring of antimicrobial residues in Danish finishing pigs
}

\author{
Lis Alban $^{\mathrm{a}, *}$, Helene Rugbjerg ${ }^{\mathrm{b}}$, Jesper Valentin Petersen ${ }^{\mathrm{a}}$, Liza Rosenbaum Nielsen ${ }^{\mathrm{c}}$ \\ a Danish Agriculture E Food Council, Axeltorv 3, DK-1609 Copenhagen V, Denmark \\ b Danish Veterinary and Food Administration, Stationsparken 31-33, 2600 Glostrup, Denmark \\ c University of Copenhagen, Grønnegårdsvej 8, DK-1870 Frederiksberg C, Denmark
}

\section{A R T I C L E I N F O}

\section{Article history:}

Received 6 October 2015

Received in revised form 7 March 2016

Accepted 15 April 2016

\section{Keywords:}

Penicillin

Tetracycline

Residues

Pig meat

Scenario tree modelling

\begin{abstract}
A B S T R A C T
In Denmark, a monitoring program for residues of antimicrobials in pork is in place involving annual testing of around 20,000 samples from finishing pigs corresponding to $0.1 \%$ of the animals slaughtered. Annually, zero to two samples are found above the maximum residue limit. Both authorities and industry have expressed interest in adjusting the monitoring to a risk-based system. The objective of this study was to assess the opportunities and consequences of the monitoring considering: 1 ) replacing the current bioassay with high-performance liquid chromatography-mass spectrometry (HPLC LC-MS/MS), 2) replacing kidney with muscles as sample matrix, and 3) using indicators to identify high-risk (HR) herds and increase sampling intensity in these herds, lowering sampling in the low-risk (LR) herds, while aiming at continued detection of similar numbers of test-positives at the lowest possible costs.

A state-of-the-art stochastic scenario tree modelling approach including economic evaluation of different model outcomes was used. A total of six scenarios were run for penicillin and tetracycline, respectively. Relevant information was obtained through the literature, statistical analysis of existing data as well as consultations with laboratory and slaughterhouse experts. Abattoir recordings of chronic pleuritis were used as an indicator for finishing pig herds $(\mathrm{HR}=$ within-herd prevalence $>40 \%)$. Such risk-based monitoring would have to use muscles and not kidneys, because of logistic challenges in identifying and storing of plucks until testing. However, the bioassay cannot be used on muscle tissue due to low sensitivity for tetracyclines. Different plausible combinations of sample sizes were also modelled.

The HPLC LC-MS/MS method detected the same number of cases compared to the bioassay when kidney was used as matrix. HPLC LC-MS/MS has a higher sensitivity when used on muscle but it is almost twice as costly as the bioassay. Risk-based sampling resulted in detection of more residue cases with higher cost-effectiveness than random monitoring. Sampling 7500 HR pigs and 5000 LR pigs resulted in the most cost-effective monitoring among the alternative scenarios. The associated costs would increase by 4\%. A scenario involving testing of $5000 \mathrm{HR}$ and $5000 \mathrm{LR}$ animals would result in slightly fewer positives, but $17 \%$ savings in costs. The advantages of using HPLC LC-MS/MS compared to the bioassay are a fast response and a high sensitivity for all relevant substances used in pigs. The Danish abattoir companies have implemented a risk-based monitoring similar to the above per January 2016.
\end{abstract}

(c) 2016 Elsevier B.V. All rights reserved.

\section{Introduction}

Withdrawal periods for veterinary medical products are established to prevent treated animals and hereby products from treated animals from entering the food chain too soon after treatment. Such withdrawal periods are based on Maximum Residue Limits (MRL). However, if the withdrawal periods are not complied with,

\footnotetext{
* Corresponding author.

E-mail address: lia@lf.dk (L. Alban).
}

residues of pharmacologically active substances or their metabolites above MRL might be found in animal-derived food products, posing a potential risk to human health (Anon., 2010).

The European Union (EU) Member States are required to implement residue monitoring in live animals and animal products (Anon., 1996). The EU Directive 96/23 prescribes that a minimum of $0.01 \%$ of the pigs slaughtered annually in each country are tested for residues of antibacterial substances through official monitoring (Anon., 2009). Currently, the annual number of finishing pigs slaughtered in Denmark is around 20 million. Around 2000 samples - corresponding to $0.01 \%$ of the slaughter population - are tested for 


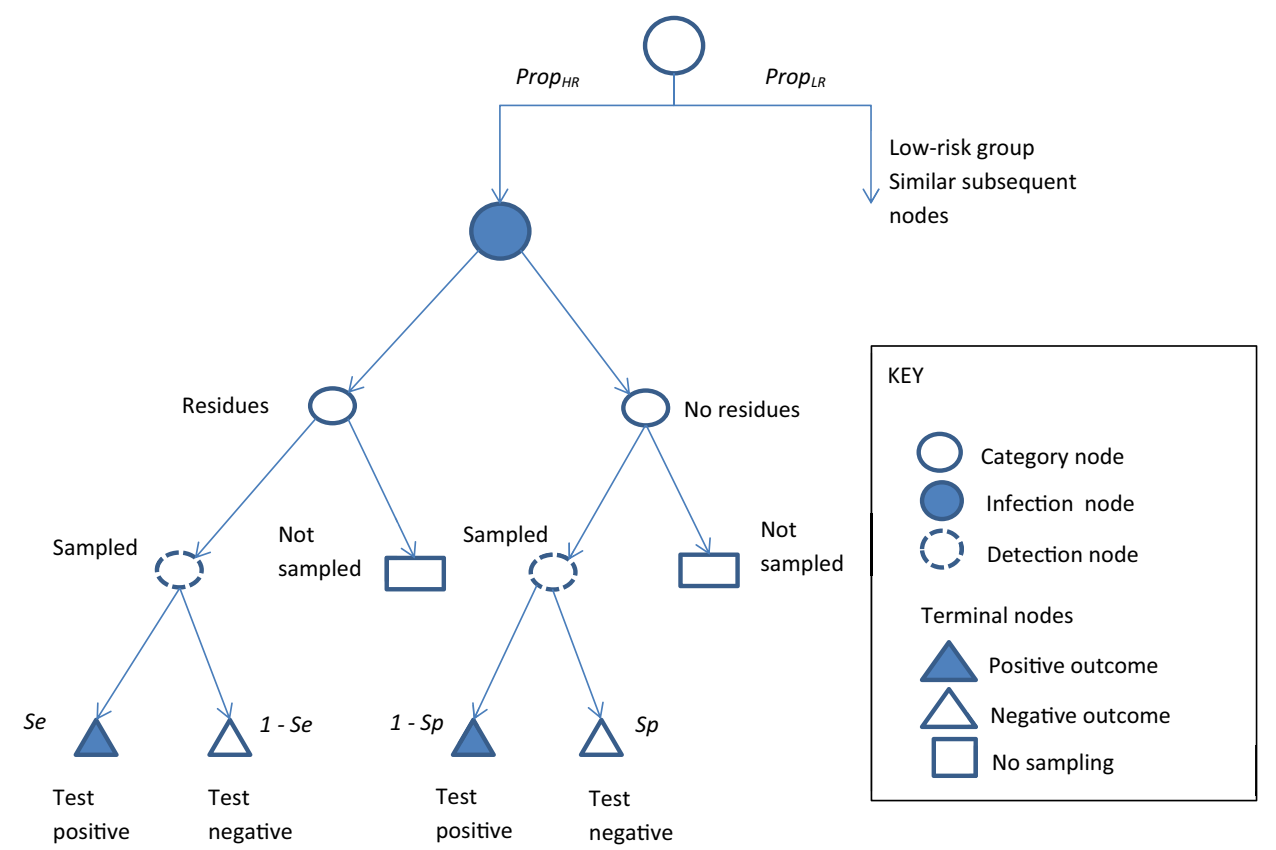

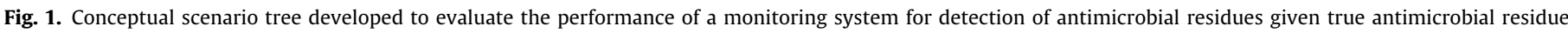

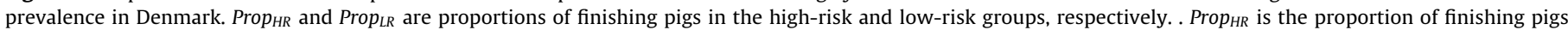
sampled in the high-risk subpopulation.

residues of antimicrobials through the official Danish national monitoring program. Another 17,000 samples $(0.085 \%)$ are collected and tested for residues of antimicrobials through the Danish abattoirs' own-check program, which is described below. Hence, the entire monitoring for antimicrobial residues includes close to $0.1 \%$ of the finishing pigs slaughtered in Denmark.

The substances found in the residue surveillance are not reflecting the general use of antimicrobials in pigs, because injectables in general have a higher likelihood of resulting in presence of residues in the meat than per oral medicine, which is not necessarily absorbed but acting locally in the intestines (Alban et al., 2014). Furthermore, residues are more likely to be present in animals treated close to time of slaughter, and therefore are more likely to be found in slaughter pigs that have recently been ill.

In the Danish own-check, samples are analysed by use of a bioassay consisting of a microbiological four-plate test (NMKL 121,2004 ) followed by a chemical verification. Since 2013 , the chemical verification consists of using high-performance liquid chromatography-mass spectrometry (HPLC LC-MS/MS). Moreover, since January 2013 samples are analysed directly by HPLC LC-MS/MS in the national program (Olsen, 2015). Currently, the Danish abattoir companies are considering replacing the bioassay with HPLC LC-MS/MS. This would eliminate the potential problem related to using different analytical methods in the two parts of the programme.

Monitoring data collected over more than a decade indicate that the true prevalence of antimicrobial residues above the MRL is negligible in Danish finishing pigs (around 0.01\%) (Baptista et al., 2012). In this situation, a risk-based approach targeting the monitoring activities to high-risk sub-populations might make it possible to reduce the number of samples taken without jeopardizing food safety, or even potentially improving food safety (Stärk et al., 2006; Hadorn and Stärk, 2008; Presi et al., 2008; Baptista et al., 2012).

According to the EU Directive, national residue monitoring should - in general - be targeted to high-risk animals using the following minimum criteria: sex, age, species, fattening system, all available background information, and all evidence of misuse or abuse of antimicrobials (Anon., 1996). In Denmark, this is interpreted as a higher sampling intensity in sows compared to finishing pigs as well as repeated testing in herds with previous findings of antimicrobial residues. In a future revision of the EU Directive, which is expected within in a few years, the goal is most likely to adopt a more risk-based monitoring.

The objective of this study was to investigate the opportunities and consequences of a risk-based approach to monitor antimicrobial residues in the Danish finishing pigs at slaughter. The specific objective was to compare the performance of two different diagnostic tests (HPLC LC-MS/MS versus a biological method) and sampling strategies (risk-based versus random). To enable such comparisons, a stochastic scenario tree model was built for estimation of costs and effects of changed sampling and testing strategies.

\section{Materials and methods}

The selected approach to address the study objectives is adapted from a state-of-the-art method developed over the last decade for use in quantitative veterinary epidemiology related to evaluation of the performance of surveillance programs. The approach is welldescribed and exemplified in international publications (Martin et al., 2007), and has been used in previous studies of related nature, e.g. Hadorn and Stärk (2008), Alban et al. (2008), Calvo-Artavia et al. (2012) and Foddai et al. (2015).

\subsection{Scenario tree model structure}

A stochastic scenario tree is a way to describe the detailed structure of the different components of a surveillance programme. The tree consists of mainly three different types of nodes: infection nodes, detection nodes and category nodes (Fig. 1). A stochastic scenario tree simulation model was developed as described by Martin et al. (2007), but modified to fit the circumstances being modeled here. The terminology and abbreviations are also slightly different from those used in the original publication by Martin et al. (2007) to describe the system being modeled.

The population of finishing pigs slaughtered in Denmark during a 1-year period (Spop) was divided into subpopulations. Within 
Table 1

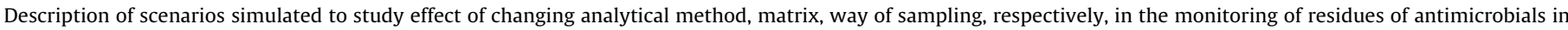
Danish finishing pigs.

\begin{tabular}{|c|c|c|c|c|c|c|c|}
\hline & & \multicolumn{6}{|c|}{ Scenario number } \\
\hline & & $1^{\mathrm{a}}$ & 2 & 3 & 4 & 5 & 6 \\
\hline \multirow[t]{2}{*}{ Analytic method } & Bioassay $^{\mathrm{b}}$ & + & & & & & \\
\hline & HPLC LC-MS/MS & & + & + & + & + & + \\
\hline \multirow[t]{2}{*}{ Matrix } & Kidney & + & + & & & & \\
\hline & Muscle & & & + & + & + & + \\
\hline \multirow[t]{3}{*}{ Way of sampling } & Random & + & + & & & & \\
\hline & Risk-based $^{\mathrm{c}}(\mathrm{RR}=2)$ & & & + & + & & \\
\hline & Risk-based $^{\mathrm{c}}(\mathrm{RR}=3)$ & & & & & + & + \\
\hline \multirow[t]{3}{*}{ Sample size } & 20,000 & + & + & & & & \\
\hline & $5,000 \mathrm{HR}^{\mathrm{d}}+5000 \mathrm{LR}^{\mathrm{d}}$ & & & + & & + & \\
\hline & $7,500 \mathrm{HR}^{\mathrm{d}}+5000 \mathrm{LR}^{\mathrm{d}}$ & & & & + & & + \\
\hline
\end{tabular}

a Current scenario.

b The bioassay consisted of a biological four-plate method (NMKL 121, 2004) followed by chemical verification of positive samples.

c It was assumed that finishing pigs from herds with $>40 \%$ prevalence of chronic pleuritis were associated with RR $=2$ or RR $=3$ of detecting residues at slaughter compared to pigs from herds with a prevalence $\leq 40 \%$ - based on Alban et al. (2014).

d $\mathrm{HR}=$ high risk; LR = low risk.

Table 2

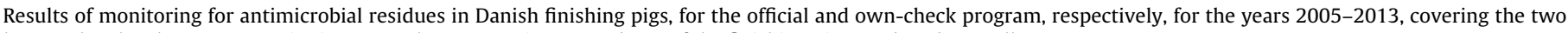
largest slaughterhouse companies in Denmark, representing around $88 \%$ of the finishing pigs produced annually.

\begin{tabular}{|c|c|c|c|}
\hline Kind of monitoringYear & Total No. of samples & No. of confirmed samples $>M_{R L}{ }^{a}$ & Substances identified \\
\hline \multicolumn{4}{|l|}{ Official program ${ }^{\mathrm{b}}$} \\
\hline 2005 & 1002 & 0 & n.r. \\
\hline 2006 & 1009 & 0 & n.r. \\
\hline 2007 & 804 & 0 & n.r \\
\hline 2008 & 809 & 0 & n.r \\
\hline 2009 & 812 & 0 & n.r. \\
\hline 2010 & 1414 & 0 & n.r. \\
\hline 2011 & 1427 & 0 & n.r. \\
\hline 2012 & 1426 & 0 & n.r. \\
\hline 2013 & 1628 & 0 & n.r. \\
\hline \multicolumn{4}{|l|}{ Own-check program ${ }^{c}$} \\
\hline 2005 & 18,910 & 0 & n.r. \\
\hline 2006 & 17,956 & 1 & Benzylpenicillin \\
\hline 2007 & 17,612 & 1 & Benzylpenicillin \\
\hline 2008 & 22,806 & 2 & Doxycycline \& Benzylpenicillin \\
\hline 2009 & 21,686 & 1 & Doxycycline \\
\hline 2010 & 16,191 & 2 & Benzylpenicillin (2) \\
\hline 2011 & 19,361 & 0 & n.r. \\
\hline 2012 & 14,240 & 1 & Tularthromcin $^{\mathrm{d}}$ \\
\hline 2013 & 14,262 & 0 & n.r. \\
\hline
\end{tabular}

n.r. $=$ not relevant.

a $\mathrm{MRL}=$ Maximum residue level accepted legally.

b From 2007 to 2012, the official samples were analysed by use of a bioassay consisting of a biological four-plate method (NMKL 121,2004) followed by chemical verification, while samples from 2013 were analysed using HPLC LC-MS/MS directly (Olsen, 2015).

c Samples taken as part of the own-check program were analysed by use of the bioassay.

d Tularthromycin belongs to the macrolide group.

each of the subpopulations, all animals were assumed to have equal probability of being test-positive in the basic scenarios. The unit of concern was the individual pig rather than the whole herd. Probabilities for the possible outcomes were estimated for each branch of the scenario tree (Fig. 1). Six trees were constructed representing random and risk-based sampling, use of two different analytical tests, two different assumptions regarding high-risk and low-risk population strata, and two different sampling strategies (Table 1). The investigation was limited to antibiotic residues grouped as penicillin or tetracycline, respectively. These two drug classes represent the vast majority of findings of antimicrobial residues in Danish finishinig pigs (Table 2).

\subsection{Population and risk factors}

In the simulations, the annual number of finishing pigs slaughtered was by default set to 20 million finishing pigs. This is close to the production achieved in the years 2007-2013.
Two risk factors/indicators related to presence of antibiotic residues have previously been identified: i) prior findings of residues in a herd (Alban et al., 2011) and ii) a high within-herd prevalence of chronic pleuritis (Alban et al., 2014). The first was considered to have limited practical impact in Denmark, because of the low number of positive findings ( $\leq 2$ in total per year in finishing pigs-Table 2). The latter was based on a study of nine different meat inspection lesions in finishing pig herds between July 2010 and December 2012. The prevalence of the different lesion codes was compared between finishing pig herds with findings of residues and similar herds delivering to the same abattoir in the same time period (Alban et al., 2014). Based on this analysis, it was concluded that only chronic pleuritis could be considered an indicator for increased risk of residues of antimicrobials. The risk of finding residues was around twice as high $(R R=2)$ in pigs coming from herds with a within-herd prevalence $>40 \%$ compared to herds with a prevalence $\leq 40 \%$ ). This is supported by a pilot study from the Netherlands, which indicated a 3.2 times higher probability (95\% C.I. of RR: $1.2-8.5, \mathrm{P}=0.01$ ) of finding antimicrobial 
residues in herds with a within-herd prevalence of pleuritis/lung lesions more than twice as high as the average (Jelsma et al., 2006). It was therefore decided to run one scenario assuming $R R=2$ and another scenario assuming $\mathrm{RR}=3$ (Table 1 ).

This herd-level cluster-effect was taken into account in the model by the first node in the scenario tree for scenarios 3-6. This node was a category node that divided all slaughtered animals into proportions of high-risk $\left(\operatorname{Prop}_{H R}\right)$ and low-risk $\left(\operatorname{Prop}_{L R}\right)$ for each risk factor group.

The average within-herd prevalence of chronic pleuritis in Danish finishing pigs is around 20\%. Based on data from Danish pig production, Alban et al. (2014) calculated that a cut-off of a withinherd prevalence of $40 \%$ would include around $25 \%$ of the herds in the HR-group.

\subsection{Probability of presence of antimicrobial residues}

The next node in the scenario tree was an infection (residue) node, in which the estimated true animal-level residue prevalence $\left(P_{A}\right)$ was used in the calculations to obtain effective probabilities of residue presence (EPP) within each subpopulation defined by the previous category node. To describe the true antibacterial residue prevalence $P_{A}$ in a fictive year, we used the distribution Pert $(0.00146 \% ; 0.0096 \% ; 0.034 \%)$. This was based upon Baptista et al. (2012) who provided estimates of $P_{A}$ based on data from the Danish finishing pig surveillance for the time period 2005-2009. The mode was calculated as the mean of each year's median, whereas the min and max were obtained as a mean of the lower and higher end of each year's 95\% credibility interval.

One of the most common findings of residues is benzylpenicillin, which is an injectable belonging to the penicillin G group (Table 2). The proportion of samples, where penicillin $G$ was found in finishing pigs in the years $2005-2013$ was $5 / 8$. This proportion was multiplied by the true prevalence of residues $P_{A}$ to obtain the prevalence of residues due to penicillin $G P_{A P}$. Although tularthromycin a macrolide - represents another class of antibiotics, the sensitivity (Se) and the specificity (Sp) in the HPLC LC-MS/MS are the same as for penicillin (100\%) according to the laboratory experts. Therefore, the finding of tularthromycin residues was added to the penicillin group to avoid not accounting for one finding of residues out of the eight, observed during the study period 2005-2013. Likewise, the proportion of samples where tetracycline residues was found in finishing pigs was $2 / 8$. This proportion was multiplied by the true prevalence of residues $P_{A}$ to obtain the prevalence of residues due to tetracycline $P_{A T}$.

The relative risks $(R R)$ for the high-risk (HR) group compared to the low-risk (LR) group, and the proportion of animals in the HR group were used for calculation of the adjusted risk $(A R)$ for the LR group $\left(A R_{L R}\right)$ and multiplied by the $R R$ to obtain the $A R$ of the high-risk group $\left(A R_{H R}\right)$ (Martin et al., 2007). Finally, the $A R s$ were multiplied by $P_{A}$ to calculate the $E P P$ for each risk group $\left(E P P_{L R}\right.$ and $E P P_{H R}$ ) as shown in Eqs. (1) and (2), and the probability of no residues present in the sample was calculated as (1-EPP) (CalvoArtavia et al., 2012).

$E P P_{L R}=\left(1 /\left(R R \times \operatorname{Prop}_{H R}+\left(1-\operatorname{Prop}_{H R}\right)\right)\right) \times P_{A}$

$E P P_{H R}=\left(\left(1 /\left(R R \times \operatorname{Prop}_{H R}+\left(1-\operatorname{Prop}_{H R}\right)\right)\right) \times R R\right) \times P_{A}$

where:

$E P P_{L R}$ is the effective probability of residue presence in the animals in the low-risk group,

$E P P_{H R}$ is the effective probability of residue presence for the animals in the high-risk group,

$R R$ is the relative risk in the high-risk compared to the low-risk group,
Prop $_{H R}$ is the proportion of all slaughtered pigs in the high-risk group and

$P_{A}$ is the assumed true animal prevalence.

\subsection{Scenarios to evaluate}

The next node in the scenario tree was a detection node determining the frequency of sampling and testing of the pigs in the different branches. According to the group categorisation of the population in HR and LR groups, six scenario trees were considered: one scenario representing the current surveillance system as well as five risk-based alternatives. The alternative scenarios were constructed in a way that allowed all animals in the HR-group to be subjected to an increased probability of testing, while all animals in the LR-group were subjected to a lower probability of testing (Table 1).

There were three variables to be studied in combination: 1 ) diagnostic method (HPLC LC-MS/MS versus bioassay, 2) choice of matrix (muscle versus kidney), and 3) way of sampling (risk-based versus random). However, a dialogue with the slaughterhouse experts revealed that risk-based monitoring based on chronic pleuritis would have to involve muscle samples and not kidneys, because of logistic challenges in identifying and storing of plucks until testing. Moreover, according to the laboratory experts, for muscle as a matrix the bioassay cannot be used as laboratory method because of a low sensitivity for tetracyclines. Therefore, scenarios with use of the bioassay and risk-based sampling were ruled out.

As stated above, the scenarios modeled were analysed for residues of penicillin and tetracycline, respectively.

The number of pigs sampled in the basic scenario reflecting the current monitoring was by default set to 20,000 finishing pigs per year corresponding to a slaughter population of 20 million finishing pigs, hence $0.1 \%$ of the slaughter population, i.e. the official monitoring and the abattoirs' current own-check combined. For the risk-based scenarios (scenario 3-6), the effect of two different and reduced sampling schemes was quantified-i.e. scenario 3 and 5) halving the intensity implying 10,000 samples divided into 5000 pigs from the HR-group and 5000 pigs from the LR-group, or scenario 4 and 6) testing 7500 pigs from the HR-group and 5000 pigs from the LR-group (Table 2). These choices were based on the abattoirs' wish to avoid an increase in costs of monitoring as well as a discussion with the marketing people in Danish Agriculture \& Food Council regarding export market requirements. This also meant that a scenario involving random sampling using HPLC LC-MS/MS on muscle samples was not considered feasible, because it would result in a substantial increase in the costs.

\subsection{Sensitivity and specificity of analytic methods}

The last step in the scenario trees was the detection node, in which the sensitivity (Se) and the specificity $(S p)$ of the two different analytical methods were modelled as pert distributions. The minimum, most likely and maximum values for the HPLC LC-MS/MS and the bioassay were estimated by expert opinion through contact to the Danish Veterinary authorities' laboratory for residue testing. The two laboratory experts (one was an expert in HPLC LC-MS/MS method, the other was an expert in the bioassay method) were interviewed by phone, and they were asked:

Sensitivity:

- What is the most likely, highest, and lowest percentage of samples with residues of penicillin or tetracycline, respectively, above MRL level in kidney or muscle, respectively, which will be detected? 
Specificity:

- What is the most likely, highest, and lowest percentage of samples with no residues of penicillin and tetracycline, respectively, in kidney or muscle, respectively, which could test false-positive?

\subsection{Model outputs}

For each scenario, the conditional probabilities were calculated for each branch in the tree by multiplying all proportions and probabilities. The overall probability of being test-positive $\mathrm{P}(\mathrm{T}+)$ was calculated as the sum of all branch probabilities with a $\mathrm{T}+$ outcome. The overall probability of being test-negative $\mathrm{P}(\mathrm{T}-)$ was the sum of all probabilities from branches with $\mathrm{T}$ - outcomes. The total expected number of finishing pigs being $\mathrm{T}+$ and $\mathrm{T}-$ were calculated by multiplying $\mathrm{P}(\mathrm{T}+)$ and $\mathrm{P}(\mathrm{T}-)$, respectively, with the total number of finishing pigs slaughtered per year (Spop).

The probability of false-positive test results was calculated for each branch representing animals without residues above MRL $(\mathrm{R}-)$ by multiplying the relevant proportion and conditional probabilities (Prop, 1-EPP, sampling probability and 1-Sp) in the given branch (Fig. 1). This was converted to the number of false-positive test results in the given branch by multiplying with the number of finishing pigs slaughtered per year (SPOp). Finally, the numbers from each R- branch were summed up to obtain the total number of false-positive test results $(n F P)$ in the given monitoring scenario. The same procedure was used to obtain the total number of detected true residue cases $(n D R C)$ in the branches representing animals with residues above MRL (i.e. using the relevant Prop and the conditional probabilities EPP, sampling probability and $S e$ ).

The expected number of cases of finishing pigs with residues above MRL (Cpresent) was calculated as the sum of the expected number of finishing pigs with presence of residues in each risk group using the following equation (Eq. (3)):

Cpresent $=\left(\left(\right.\right.$ SPop $\left.\left.\times \operatorname{Prop}_{L R}\right) \times E P P_{L R}\right)+\left(\left(S P o p \times\right.\right.$ Prop $\left.\left._{H R}\right) \times E P P_{H R}\right)$

where:

SPop is the total number of pig population slaughtered per year, set to 20 million in all scenarios

Prop $_{L R}$ is the proportion of slaughtered pigs that belongs to the low-risk group, set to $75 \%$ in the risk-based scenarios

Prop $_{H R}$ is the proportion of slaughtered pigs that belongs to the high-risk group, set to $25 \%$ in the risk-based scenarios, and

$E P P_{L R}$ and $E P P_{H R}$ are the probabilities of residue presence for the LR and HR-group, respectively, calculated by use of Eqs. (1) and (2).

Initially, a Poisson distribution was used to describe the simulated number of cases detected with residues. However, as most outputs were 0,1 or 2 , this was not very helpful to identify differences in outputs of the various scenarios. Therefore, it was decided to abandon the use of a Poisson distribution, and use normal distributions allowing for decimal numbers in the output. To get the number of undetected cases ( $n U R C$ ) for each scenario the total number of detected cases, $n D R C$, was subtracted from Cpresent. The surveillance system sensitivity (SSSe) for each scenario was calculated by dividing the $n D R C$ by the Cpresent. The SSSe represents the proportion of cases detected by the surveillance program.

\subsection{Simulations}

The models were set up in @Risk 6 (Palisade Corporation ${ }^{\circledR}$, Middlesex, UK) and run with 10,000 iterations and random seed. To account for uncertainty, the input parameters were described by use of distributions. Sensitivity analysis was performed by regres- sion analysis for each scenario, identifying significant outputs, displayed as "tornado" type charts.

\subsection{Input for cost comparison}

The costs of one screening analysis when performed in large scale by the largest slaughterhouse company in Denmark were obtained from the head of laboratory of the slaughterhouse company (Andersen, personal communication, 2015). Accordingly, the cost associated with use of the HPLC LC-MS/MS method was estimated to $€ 10$ per sample, and $€ 6$ for a sample subjected to the bioassay. These figures are without depreciation of the laboratory equipment. The price of the HPLC LC-MS/MS equipment was $€ 33,000$, VAT exclusive (Kirkeby, personal communication, 2015). Moreover, there will be costs related to setting up the information system to identify which pigs to sample.

\section{Results}

According to the two experts contacted, the difference between the two diagnostic methods regarding test characteristics was limited when kidney was used as matrix (Table 3). Therefore, the same number of samples positive above MRL was expected, if the bioassay was replaced by the HPLC LC-MS/MS both for penicillin and tetracycline, when using kidney as the sampling matrix. According to the experts, the specificity of the two diagnostic methods was close to one implying no false-negative test results.

The model predicted that the average number of samples detected above MRL in the current program would be 1.77 for penicillin and 0.55 for tetracycline per year. The variation in mean total number of detected cases was very low; ranging from 1.48 in scenario 3 , to 2.32 in scenario 1 and 2 . Hence, very low numbers of positive samples would be expected. This is in accordance with the figures displayed in Table 2, where it is noted that in some years no positives were found, whereas in other years up to two positives were detected. Moreover, the vast majority of positive carcasses were not found in the monitoring program; In all scenarios, around 2467 carcasses with residues above MRL were estimated to pass through the production chain unnoticed despite of the large number of samples taken as a part of the program. This is in line with the low SSSe, which varied from $0.06 \%$ to $0.09 \%$ (Table 4 ).

The costs of using HPLC LC-MS/MS on an individual sample were $67 \%$ higher than the costs of using the bioassay (Table 4 ). The use of risk-based sampling led to a more cost-effective monitoring compared to using HPLC LC-MS/MS for the random sampling of residues (scenario 3-6 versus scenario 2). Assuming a RR of 3 between the HR and the LR-groups related to chronic pleuritis as well as sampling 7500 animals in the HR group and 5000 animals in the LR group led to approximately the same mean number of positive samples as random monitoring of 20,000 animals on average (2.26 versus 2.32-Scenario 6 versus scenario 1 and 2 in Table 4). If a RR of 2 was assumed, then a slightly lower average value was obtained (1.97-Scenario 4 in Table 4). Hence, the variation in mean number of detected cases was very low, but the difference in costs was large; ranging from $€ 100,000$ in scenarios 3 and 5 to $€ 200,000$ in scenario 2. Scenario 6 had the lowest costs per case detected among the risk-based scenarios investigated. Scenario 3 and 5 in fact resulted in $17 \%$ lower costs than the current programme, but the costs per case detected were higher than for the current program (Table 4).

The sensitivity analyses revealed that the input variables with the highest impact on the output were the variables describing the effective probability of presence of residues $(E P P)$ in the animals originating from pigs in the HR or LR groups, respectively. The $E P P$ is very precisely estimated because several years of monitoring data involving thousands of samples were included in the estimate 
Table 3

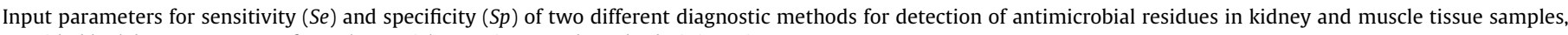
provided by laboratory experts from the Danish Veterinary and Food Administration, 2014.

\begin{tabular}{|c|c|c|c|c|c|c|}
\hline Method & Antibiotic & Matrix & Parameter & Min & Mode & Max \\
\hline \multirow[t]{8}{*}{ Bioassay $^{\mathrm{a}}$} & \multirow[t]{4}{*}{ Penicillin } & \multirow[t]{2}{*}{ Kidney } & $\mathrm{Se}$ & 0.95 & 0.95 & 1 \\
\hline & & & $S p$ & 1 & 1 & 1 \\
\hline & & \multirow[t]{2}{*}{ Muscle } & $\mathrm{Se}$ & 0.96 & 0.96 & 1 \\
\hline & & & $S p$ & 1 & 1 & 1 \\
\hline & \multirow[t]{4}{*}{ Tetracycline } & \multirow[t]{2}{*}{ Kidney } & $\mathrm{Se}$ & 0.8 & 0.875 & 1 \\
\hline & & & $S p$ & 1 & 1 & 1 \\
\hline & & \multirow[t]{2}{*}{ Muscle } & Se & 0 & 0 & 0 \\
\hline & & & $S p$ & 1 & 1 & 1 \\
\hline \multirow{8}{*}{$\begin{array}{l}\text { HPLC } \\
\text { LC-MS/MS }\end{array}$} & \multirow[t]{4}{*}{ Penicillin } & \multirow[t]{2}{*}{ Kidney } & Se & 1 & 1 & 1 \\
\hline & & & $S p$ & 1 & 1 & 1 \\
\hline & & \multirow[t]{2}{*}{ Muscle } & Se & 1 & 1 & 1 \\
\hline & & & $S p$ & 1 & 1 & 1 \\
\hline & \multirow[t]{4}{*}{ Tetracycline } & \multirow[t]{2}{*}{ Kidney } & Se & 1 & 1 & 1 \\
\hline & & & $S p$ & 1 & 1 & 1 \\
\hline & & \multirow[t]{2}{*}{ Muscle } & Se & 1 & 1 & 1 \\
\hline & & & $S p$ & 1 & 1 & 1 \\
\hline
\end{tabular}

a The bioassay consisted of a microbiological four-plate test (NMKL 121, 2004) followed by a chemical verification of positive samples.

Table 4

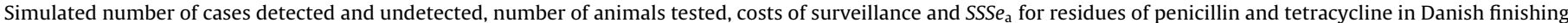
pigs, for six scenarios involving different sample matrices and sample size combinations.

\begin{tabular}{|c|c|c|c|c|c|c|c|c|c|}
\hline \multirow{2}{*}{$\begin{array}{l}\text { Scenario } \\
\text { Sampling }\end{array}$} & \multirow[t]{2}{*}{ Antimicrobial } & \multicolumn{2}{|c|}{ Mean No. of cases >MRL ( $90 \% \mathrm{CI})$} & \multicolumn{3}{|c|}{ No. of animals tested in } & \multicolumn{2}{|c|}{ Cost of sampling } & \multirow{2}{*}{$\begin{array}{l}\text { SSSe } \\
\%\end{array}$} \\
\hline & & Detected & Undetected & $\mathrm{HR}^{\mathrm{b}}$ group & $\mathrm{LR}^{\mathrm{b}}$ group & Total & Total $(€)$ & $€$ per case & \\
\hline 1 Current random ${ }^{c}$ & $\begin{array}{l}\text { Penicillin } \\
\text { Tetracycline } \\
\text { Total }\end{array}$ & $\begin{array}{l}1.77(0.57-3.30) \\
0.55(0.17-1.01) \\
2.32\end{array}$ & $\begin{array}{l}1850(591-3439) \\
617(197-1147) \\
2467\end{array}$ & 5000 & 15,000 & 20,000 & 120,000 & 51,724 & 0.09 \\
\hline 2 Alternative random ${ }^{\mathrm{d}}$ & $\begin{array}{l}\text { Penicillin } \\
\text { Tetracycline } \\
\text { Total }\end{array}$ & $\begin{array}{l}1.77(0.57-3.30) \\
0.55(0.18-1.01) \\
2.32\end{array}$ & $\begin{array}{l}1850(591-3439) \\
617(197-1146) \\
2467\end{array}$ & 5000 & 15,000 & 20,000 & 200,000 & 86,207 & 0.09 \\
\hline $\begin{array}{l}3 \text { Risk-based } \\
\text { RR }=2\end{array}$ & $\begin{array}{l}\text { Penicillin } \\
\text { Tetracycline } \\
\text { Total }\end{array}$ & $\begin{array}{l}1.11(0.36-2.07) \\
0.37(0.12-0.69) \\
1.48\end{array}$ & $\begin{array}{l}1850(591-3440) \\
617(197-1147) \\
2467\end{array}$ & 5000 & 5000 & 10,000 & 100,000 & 67,568 & 0.06 \\
\hline $\begin{array}{l}4 \text { Risk-based } \\
\text { RR }=2\end{array}$ & $\begin{array}{l}\text { Penicillin } \\
\text { Tetracycline } \\
\text { Total }\end{array}$ & $\begin{array}{l}1.48(0.47-2.75) \\
0.49(0.16-0.92) \\
1.97\end{array}$ & $\begin{array}{l}1850(591-3440) \\
617(197-1147) \\
2467\end{array}$ & 7500 & 5000 & 12,500 & 125,000 & 63,452 & 0.08 \\
\hline $\begin{array}{l}5 \text { Risk-based } \\
\text { RR = } 3\end{array}$ & $\begin{array}{l}\text { Penicillin } \\
\text { Tetracycline } \\
\text { Total }\end{array}$ & $\begin{array}{l}1.23(0.40-2.30) \\
0.41(0.13-0.77) \\
1.64\end{array}$ & $\begin{array}{l}1850(591-3440) \\
617(197-1147) \\
2467\end{array}$ & 5000 & 5000 & 10,000 & 100,000 & 60,976 & 0.07 \\
\hline $\begin{array}{l}6 \text { Risk-based } \\
\text { RR }=3\end{array}$ & $\begin{array}{l}\text { Penicillin } \\
\text { Tetracycline } \\
\text { Total }\end{array}$ & $\begin{array}{l}1.70(0.54-3.16) \\
0.56(0.18-1.05) \\
2.26\end{array}$ & $\begin{array}{l}1850(591-3439) \\
617(197-1146) \\
2467\end{array}$ & 7500 & 5000 & 12,500 & 125,000 & 55,310 & 0.09 \\
\hline
\end{tabular}

a Surveillance system sensitivity.

b $\mathrm{HR}=$ high risk; LR = Low risk.

c Current surveillance consists of a bioassay called the four-plate test (NMKL 121, 2004) applied to kidney samples followed by chemical verification of positive samples.

d In the alternative scenarios 2-5 the bioassay was replaced by direct verification using HPLC LC-MS/MS on muscle samples.

e Finishers from herds with $>40 \%$ chronic pleuritis were assumed to have higher risk of residues according to Alban et al. (2014).

as well as information of test characteristics provided by laboratory experts. However, the relative risk (RR) for HR versus LR was associated with a higher uncertainty. Therefore scenario analysis was undertaken by assuming $\mathrm{RR}=2$ or $\mathrm{RR}=3$-see scenario $3-6$ in Table 4.

\section{Discussion}

\subsection{General performance}

The results show that the prevalence of residues of antimicrobials in Danish finishing pigs is negligible, but they also show that most cases remain undetected despite that thousands of samples are taken and analysed. This is reflected in the low SSSe in the current random sampling and the alternative risk-based scenarios. Still, the surveillance is relevant, because it is important to show to the farmers that withdrawal periods should be complied with.
The value of the surveillance also lies in demonstrating to consumers, trade partners, and national and international authorities that efforts are done to prevent residues of antimicrobials in meat. Because consumers perceive residues as something that is indeed unwanted in meat (TNS Opinion and Social, 2010), although Berends et al. (2001), Baptista et al. (2010) and Alban et al. (2014) have interpreted presence of residues of antimicrobials more as a public health concern than a true food safety issue.

Testing of a low-prevalent condition requires a large number of samples, and most samples are test-negative. In such a situation, risk-based sampling becomes relevant (Stärk et al., 2006; Hadorn and Stärk, 2008). The question is which factors are effective, efficient and practical. We have so far only been able to identify one suitable indicator for residues of antimicrobials in finishing pigs: the within-herd prevalence of chronic pleuritis measured at the time of slaughter (dichotomized into $>40 \%$ and $\leq 40 \%$ ), but further investigations might identify other relevant risk factors or indica- 
tors. Other herd-level cluster-effects might be relevant for the risk of residues being present in pigs going to slaughter, including the farmer's system for ensuring that the withdrawal times are kept. However, this type of information is not available to the monitoring system and hence cannot be used for risk-based sampling.

\subsection{Economic considerations}

According to the information from one of the abattoirs, the HPLC LC-MS/MS diagnostic method is almost twice as expensive as the bioassay. An interesting question was therefore, whether the use of risk-based sampling could compensate for the increased costs? This was apparently the case, when it was assumed that the animals from herds with $>40 \%$ chronic pleuritis were associated with a two or three times higher risk of having residues above MRL. Here, a scenario involving either 5000 or $7500 \mathrm{HR}$ finishing pigs as well as 5000 LR finishing pigs would only result in a slightly lower number of positives compared to in the current program involving 20,000 samples (Table 4). It is questionable whether such small absolute changes in the number of test-positives will be noticeable at all in the monitoring, and whether it will have any consequences for the aims of the program.

Information about costs of the laboratory analyses was provided by the abattoir company and was without depreciation of the equipment and based on large-scale sampling. The prices may easily be higher, if it is not the slaughterhouse's own laboratory which is analysing the samples. This may be the case for small abattoirs.

\subsection{Logistic challenges and advantage of the novel approach}

Implementing a risk-based sampling approach would require a change of the matrix from kidney to muscle because of logistic problems when trying to identify the animals that need to be tested compared to a program using random sampling. Here, an automatic identification system based on previous records from the herds can be applied, facilitating the sampling at the slaughterhouse. A similar system is already in place for Salmonella in Danish finishing pigs, where the pigs to be sampled in the cooling room are identified automatically over an entire slaughterday (Alban et al., 2012).

The HPLC LC-MS/MS method is more sensitive than the bioassay at MRL for residues of other antimicrobials used in the pig production such as macrolides. Hence, more substances may be found in the years to come, although the official samples from 2012 to 2013 did not reveal any positives despite of partial use of the HPLC LC-MS/MS (Table 2).

Concurrent analysis for a larger number of substances opens up for use of monitoring as a way of documenting whether illegal/prohibited drugs are used for livestock in the abattoirs' own-check. An example of this could be cephalosporins which are prohibited by the Danish pig industry (Alban et al., 2013). However, some substances - such as tiamulins and aminoglycosides cannot be analysed easily by the HPLC LC-MS/MS method, because they would require a separate purification procedure and chemical analysis.

Use of HPLC LC-MS/MS implies that results (including substance and concentration) become available within a few days. This will make it easier to identify the reason for the presence during the mandatory follow-up visit to the herd, which is needed within a few days to ensure that the farmer can deliver pigs for slaughter the following week. Today, this is more difficult, because time for full diagnosis is longer (several days to weeks) after a positive reaction in the bioassay.

We suggest to include both HR and LR pigs in the monitoring. If only HR pigs were included in the monitoring for residues, then only one fourth of the Danish pig population would be covered in the monitoring. This might result in some farmers losing the incentive to comply with the withdrawal period. Moreover, there are other reasons for finding residues than a high within-herd prevalence of chronic pleuritis as described by Alban et al. (2014); therefore, the monitoring program needs to include samples taken at random or in the LR group. It is expected that reducing the sample frequency in the LR group will generally not reduce the preventive effect from the monitoring program. An increased sampling in the HR group may - if communicated effectively - have a positive effect. In all cases, information campaigns should be launched to all farmers from time to another. Here, focus should be on use of correct marking of treated animals to prevent that these are delivered too early to slaughter.

The HPLC LC-MS/MS method is capable of finding residues at levels lower than MRL implying that it will be possible to monitor the level of residues of specific substances in the pigs slaughtered even if they are not above MRL. The usefulness of this has been pointed to by Olsen (2015), who focused on residues of tetracyclines in pork exported to countries with lower MRL than in the EU-such as Russia.

The current monitoring within the EU shows that $0.13 \%$ of the samples from pig meat were non-compliant, over-all speaking. However, the monitoring programs vary between Member States, which makes it difficult to compare results (EFSA, 2014). The EU Directive about residue monitoring will be up for negotiations within a couple of years. It is expected that the future residue monitoring of antimicrobial residues shall be based on guidelines produced by EFSA, and hopefully the present study can act as a valuable input to these guidelines enabling a cost-effective, harmonized monitoring in all EU Member States-also for the inspiration of countries outside the EU.

\section{Conclusion}

The more costly HPLC LC-MS/MS can replace bioassay as a diagnostic method in the own-check for antimicrobial residues in finishing pigs without an increase in total costs, if risk-based sampling is applied. Sampling matrix will have to be muscle and not kidney because of logistic challenges. This will result in a fast response and a high sensitivity for a concurrent analysis of almost all relevant substances used in pig production, hereby, providing more effective responses to detection of residues of antimicrobials in finishing pigs.

\section{Epilogue}

Based on the results shown in the present study, the Danish pig industry decided to change to HPLC LC-MS/MS in their owncheck program by January 2016. The program involves risk-based sampling using the within-herd prevalence of chronic pleuritis prevalence as an indicator of high-risk herds (within-herd prevalence $>40 \%$ ) including $0.025 \%$ randomly selected finishing pigs within the HR-group and $0.025 \%$ randomly selected finishing pigs in the LR-group.

\section{Acknowledgements}

Gitte Geertsen, chemist, and Birgitte Herbert Nielsen, microbiologist, both from the Danish Veterinary and Food Administration laboratory are acknowledged for expert opinion regarding sensitivity and specificity for the diagnostic methods. Jens Andersen, head of laboratory, and Kirsten Kirkeby, quality assurance supervisor, at Danish Crown Abattoir Company are acknowledged for input to the economic part of the analysis as well the constraints of the method. Håkan Vigre from the Danish Food Institute is acknowledged for discussions regarding the modelling part. 


\section{References $^{1}$}

Anon., 1996. Council Directive 96/23/EC of 29 April 1996 on measures to monitor certain substances and residues thereof in live animals and animal products. The EU Commission. http://ec.europa.eu/food/food/chemicalsafety/residues/ council_directive_96_23ec.pdf.

Anon., 2009. Regulation (EC) 470/2009 of 6 May 2009 laying down Community procedures for the establishment of residue limits of pharmacologically active substances in foodstuffs of animal origin. http://eur-lex.europa.eu/legalcontent/EN/TXT/PDF/? uri=CELEX:32009R0470\&rid=2.

Anon., 2010. Commission Regulation (EU) No 37/2010 of 22 December 2009 on pharmacologically active substances and their classification regarding maximum residue limits in foodstuffs of animal origin. http://eur-lex.europa. eu/legal-content/EN/TXT/PDF/

?uri=CELEX:32010R0037\&qid=1436435606564\&from=EN.

Alban, L., Boes, J., Kreiner, H., Petersen, J.V., Willeberg, P., 2008. Towards a risk-based surveillance for Trichinella spp. in Danish pig production. Prev. Vet. Med. 87, 340-357.

Alban, L., Steenberg, B., Thune-Stephensen, F., Olsen, A.-M., Petersen, J.V., 2011. Overview on Current Practices of Meat Inspection in the EU. Scientific Report Conducted for EFSA by the Danish Agriculture and Food Council, 152 pp. http://www.efsa.europa.eu/en/supporting/doc/190e.pdf.

Alban, L., Baptista, F.M., Møgelmose, V., Sørensen, L.L., Christensen, H., Aabo, S., Dahl, J., 2012. Salmonella surveillance and control for finishing pigs and pork in Denmark-a case study. Food Res. Int. 45, 656-665.

Alban, L., Dahl, J., Andreasen, M., Petersen, J.V., Sandberg, M., 2013. Possible impact of the yellow card antimicrobial scheme on meat inspection lesions in Danish finisher pigs. Prev. Vet. Med. 108, 334-341.

Alban, L., Pacheco, G., Petersen, J.V., 2014. Risk-based surveillance of antimicrobial residues-identification of potential risk factors. Prev. Vet. Med. 114, 88-95.

Baptista, F.M., Alban, L., Olsen, A.M., Petersen, J.V., Toft, N., 2012. Evaluation of the antibacterial residue surveillance program in Danish pigs using Bayesian methods. Prev. Vet. Med. 106, 308-314.

Baptista, F.M., Alban, L., Olsen, A.M., Petersen, J.V., 2010. Epidemiological evaluation of the residue surveillance program in Danish pigs. Danish Agric. Food Counc. http://www.lf.dk/Aktuelt/Publikationer/Svinekod.aspx.
Berends, B.R., van den Bogaard, A.E.J.M., Van Knapen, F., Snijders, J.M.A., 2001. Veterinary public health: human health hazards associated with the administration of antimicrobials to slaughter animals. Vet. Q. 23 (1), 2-10, http://dx.doi.org/10.1080/01652176.2001.9695068.

Calvo-Artavia, F.F., Nielsen, L.R., Alban, L., 2012. Epidemiologic and economic evaluation of risk-based meat inspection for bovine cysticercosis in Danish cattle. Prev. Vet. Med. 1, 108 (4), 253-261.

EFSA, 2014, Report for 2012 on the results from the monitoring of veterinary medicinal product residues and other substances in live animals and animal products. Technical Report. EFSA supporting publication. 2014:EN-540. http:// www.efsa.europa.eu/sites/default/files/scientific_output/files/main documents/540e.pdf.

Foddai, A., Nielsen, L.R., Willeberg, P., Alban, L., 2015. Comparison of output-based approaches used to substantiate bovine tuberculosis free status in Danish cattle herds. Prev. Vet. Med. 121, 21-29.

Hadorn, D., Stärk, K.D.C., 2008. Evaluation and optimization of surveillance systems for rare and emerging infectious diseases. Vet. Res. 39, 57-68.

Jelsma, A., Lesuis, R., Ronteltap, E., 2006. Final Report on the Data Analysis from the Visual Inspection Pilot. Dutch Food and Consumer Product Safety Authority, 36 pp.

Martin, P.A.J., Cameron, A.R., Greiner, M., 2007. Demonstrating freedom from disease using multiple complex data sources: 1: a new methodology based on scenario trees. Prev. Vet. Med. 79, 71-97.

NMKL 121, 2004. Antibacterial substances. Microbiological examination of residues of antibiotics and chemotherapeutics in kidney and muscle from carcasses (4 plate method). 2nd edition. http://www.nmkl.org/index. php?option=com_zoo\&task=item\&item_id=296\&Itemid=319\&lang=en.

Olsen, A.-M., 2015. Assessment of the additional Danish guarantees to ensure compliance with Russian standards for residues of tetracyclines in Danish pork for export. Masters Thesis. University of Copenhagen, 31 pp.

Presi, P., Stärk, K.D.C., Knopf, L., Breidenbach, E., Sanaa, M., Frey, J., Regula, G., 2008 Efficiency of risk-based vs. random sampling for the monitoring of tetracycline residues in slaughtered calves in Switzerland. Food Addit. Contam. 25 (5), 566-573.

Stärk, K.D.C., Regula, G., Hernandez, J., Knopf, L., Fuchs, K., Morris, R.S., Davies, P. 2006. Concepts for risk-based surveillance in the field of veterinary medicine and veterinary public health: review of current approaches. BMC Health Serv. Res. 6 (20).

TNS Opinion \& Social, 2010. Special Eurobarometer 354, 168 pp. http://ec.europa. eu/public_opinion/archives/ebs/ebs_354_en.pdf.

1 All links were accessed on March 2, 2016. 